\title{
Nonalkolik yağlı karaciğer hastalığında histolojik progresyon ile klinik ve laboratuvar parametrelerin ilişkisi
}

\author{
The relationship between clinical and laboratory parameters and histological progression in \\ nonalcoholic fatty liver disease \\ (D) Nalan Gülşen ÜNAL' , (D Funda YILMAZ², (DUlus Salih AKARCA 1 , DDeniz NART², (D Galip ERSÖZ1 , \\ (DZEki KARASU', (DÖmer ÖZÜTEMIZ1, (D) Fulya GÜNŞAR
}

Ege Üniversitesi Tıp Fakültesi İç Hastalıkları Anabilim Dalı, 'Tastroenteroloji Bilim Dalı, ²Patoloji Anabilim Dalı, İzmir

\begin{abstract}
Giriş ve Amaç: Nonalkolik steatohepatit nonalkolik yağlı karaciğer hastalığının ilerleyici bir formudur. Nonalkolik steatohepatit, zamanla siroz ve hepatosellüler karsinomaya sebep olabilir. Bu çalışmada nonalkolik yağı karaciğer hastalığı tanılı olgularda zamanla karaciğer histolojisindeki değişikliklerin araştırılması ve histolojik progresyonla ilişkli klinik ve laboratuvar değişkenlerin saptanması amaçlanmıştır. Gereç ve Yöntem: Bu çalışmada 1994-2009 yılları arasında hepatoloji veri tabanına kayıtı toplam 783 nonalkolik yağlı karaciğer hastalıklı olgu retrospektif olarak tarandı. En az 2 yıl arayla yapılan 2 karaciğer biyopsisi olan 29 hasta çalışmaya alındı. Vücut kitle indeksi, glukoz intoleransı veya diyabetes mellitus varlığı, karaciğer fonksiyon testi dahil biyokimyasal parametreler kaydedildi. Nonalkolik yağlı karaciğer hastalığı aktivite skoru steatoz, lobüler inflamasyon ve hepatosellüler balonlaşma skorlarının toplamı ile hesaplandı. Fibroz skorları ayrı rapor edildi. Bulgular:

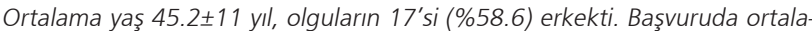
ma vücut kitle indeksi $29.5 \pm 4 \mathrm{~kg} / \mathrm{m} 2$, $15^{\prime} \mathrm{i}$ (\%51.7) fazla kilolu, 12'si (\%41.4) obezdi. Toplam 11'inde (\%37.9) diyabetes mellitus, 6'sında (\%20.7) glukoz intoleransı vardı. Aspartat aminotransferaz düzeyi ortalama $51 \pm 36 \mathrm{IU} / \mathrm{ml}$, alanin aminotransferaz düzeyi ortalama $79 \pm 50 \mathrm{lU} / \mathrm{ml}$, albümin ortalama $4.5 \pm 0.4 \mathrm{gr} / \mathrm{dL}$, trigliserit ortalama $197 \pm 106 \mathrm{mg} / \mathrm{dL}$ saptandı. Hastaların 14 'ünde (\%48.3) "nonalkolik steatohepatit" ve 6'sında (\%20.6) basit steatoz vardı. Egzersiz ve diyet önerisiyle kontrol biyopsi için medyan takip aralığı 4.8 yıl (2-9 yıl) saptandı. Kontrol biyopsi anında vücut kitle indeksi ortalama $29.6 \pm 4 \mathrm{~kg} / \mathrm{m}^{2}$, aspartat aminotransferaz ortalama $38.8 \pm 14 \mathrm{IU} / \mathrm{ml}$, alanin aminotransferaz ortalama $59.2 \pm 32 \mathrm{IU} / \mathrm{ml}$, 13'ünde (\%44.8) diyabetes mellitus ve 7 'sinde (\%24.1) glukoz intoleransı saptandı. Ikinci karaciğer biyopsilerinde nonalkolik yağı karaciğer hastalığı aktivite skoru; 9 (\%31) hastada ilerlemiş, 17'sinde (\%58.6) gerilemiş, 3'ünde (\%10.3) aynı bulundu. Fibrozis skorunda ise 6 (\%20.1) hastada ilerleme, 3 (\%10.3) hastada ise iyileșme görüldü. Nonalkolik yağlı karaciğer hastalığı aktivite skoru ilerlemesiyle başlangıç yaşı arasında negatif, başlangı̨c vücut kitle indeksi ile pozitif korelasyon saptandi, sirasiyla $(r=-0.370, p=0.047$ ve $r=0.485, p=0.007)$. Fibrozis skoru ilerlemesiyle, başlangıç yașı arasında negatif, başlangıç vücut kitle indeksi ile pozitif ve kontrol biyopsileri anındaki aspartat aminotransferaz düzeyiyle pozitif korelasyon saptandi, sirasıly $(r=-0.503 p=0.005 ; r=0.382 p=0.04$ ve $r=0.546 p=0.007)$. Sonuç: Basit yağlanma yaşla ve yüksek vücut kitle indeksi ile ilişkili olarak nonalkolik steatohepatite progrese olabilir. Genç yaştakiler, yüksek vücut kitle indeksi ve aspartat aminotransferaz düzeyinde yükseklik olanlar fibrozis progresyonu açısından daha riskli bulunmuştur.
\end{abstract}

Anahtar kelimeler: Nonalkolik karaciğer yağlanması, nonalkolik steatohepatit, karaciğer histolojisi, nonalkolik karaciğer yağlanma aktivite skoru, fibrosiz
Background and Aims: Nonalcoholic steatohepatitis is the progressive form of nonalcoholic fatty liver disease and can cause cirrhosis and hepatocellular carcinoma. We aimed to investigate the changes in liver histology and determined the relationship between histologic progression and clinical and laboratory parameters in patients with nonalcoholic fatty liver disease. Materials and Methods: We retrospectively screened 783 patients with nonalcoholic fatty liver disease who had enrolled in the hepatology database between 1994 and 2009. Among the 783, there were 29 patients with two liver biopsies performed at least two years apart. Body mass index, presence of glucose intolerance or diabetes, and biochemical parameters including liver function test were noted. Nonalcoholic fatty liver disease activity score was the sum of steatosis, lobular inflammation, and hepatocellular ballooning scores. The fibrosis scores were reported separately. Results: Mean patient age was $45.2 \pm 11$ years, and 17 (58.6\%) patients were men. Mean body mass index was $29 \pm 4 \mathrm{~kg} / \mathrm{m} 2$, and $15(51.7 \%)$ patients were overweight and $12(41.4 \%)$ were obese. Twelve (41.4\%) patients had diabetes mellitus and five (17.2\%) patients had glucose intolerance. Mean aspartate aminotransferase level was $51 \pm 36 \mathrm{IU} / \mathrm{ml}$, mean alanine aminotransferase level was $79 \pm 50 \mathrm{IU} / \mathrm{ml}$, mean albumin level was $4.5 \pm 0.4 \mathrm{~g} / \mathrm{dL}$, and mean triglyceride level was $197 \pm 106 \mathrm{mg} / \mathrm{dL}$ at baseline. Fourteen (48.3\%) patients had nonalcoholic steatohepatitis and six (20.6\%) patients had simple steatosis. The patients followed the recommended exercises and diet for therapy, and control liver biopsies were performed. The median follow-up duration was 4.8 years (2-9). Mean body mass index was $29.6 \pm 4 \mathrm{~kg} / \mathrm{m}^{2}$, mean aspartate aminotransferase level was $38.8 \pm 14 \mathrm{IU} / \mathrm{ml}$, and mean alanine aminotransferase was $59.2 \pm 32 \mathrm{IU} / \mathrm{ml}$. Thirteen $(44.8 \%)$ patients had diabetes mellitus and seven (24.1\%) had glucose intolerance at the time when their control biopsies were collected. According to nonalcoholic fatty liver disease activity score, nonalcoholic steatohepatitis progression was detected in 9 (31\%) patients, while improvement was detected in 17 (58.6\%) patients. In control liver biopsies, nonalcoholic fatty liver disease activity score remained the same in three $(10.3 \%)$ patients. Six $(20.1 \%)$ patients experienced progression and three $(10.3 \%)$ patients showed improvement in fibrosis scores in the control biopsies. Regarding the basal parameters, age was negatively correlated and body mass index was positively correlated with the nonalcoholic steatohepatitis progression $(r=-0.370, p=0.047$ and $r=0.485, p=0.007$, respectively). The progression of fibrosis scores was negatively correlated with baseline age and positively correlated with baseline body mass index and aspartate aminotransferase levels when control biopsies were taken $(r=-0.503, p=0.005 ; r=0.382, p=0.04 ;$ and $r=0.546, p=0.007$, respectively). Conclusion: Simple steatosis may progress to nonalcoholic steatohepatitis in patients with younger age and high body mass index. Patients with younger age and higher body mass index at baseline and higher aspartate aminotransferase at the time of collecting the control biopsies were more likely to experience progression of liver fibrosis.

Keywords: Nonalcoholic fatty liver disease, nonalcoholic steatohepatitis, liver histology, nonalcoholic fatty liver disease activity score, fibrosis

Ünal NG, YIImaz F, Akarca US, et al. The relationship between clinical and laboratory parameters and histological progression in nonalcoholic fatty liver disease. The Turkish Journal of Academic Gastroenterology 2020;19:63-74. DOI: 10.17941/agd.799535

Geliş Tarihi: 15.07.2020 • Kabul Tarihi: 20.08.2020
Ege Üniversitesi Tıp Fakültesi, Gastroenteroloji Bilim Dalı, Bornova, İzmir Tel: +902323904397

E-mail:drnalanunal@gmail.com 


\section{GíRiş}

Nonalkolik yağlı karaciğer hastalığı (NAFLD) tüm dünyada sık görülen karaciğer hastalığı nedenlerinden biridir. NAYKH, basit karaciğer yağlanmasından, non alkolik steatohepatit (NASH), fibrozis, siroz ve son dönem karaciğer hastalığına dek ilerleyen kronik karaciğer hastalığı spektrumunu içeren geniş bir terminolojidir (1-4). Histolojik bulgular alkolik hepatittekilerle benzer olmasına karşılık, hastaların alkol kullanmıyor olmaları temel belirleyicidir. Kesin sınır tartışmalı olmakla beraber NAYKH için maksimum alkol alımı kadınlarda 20 gr/gün, erkeklerde $30 \mathrm{gr} /$ gün olarak kabul edilmiştir (5). NAYKH'nı tanımlamak için geçmiş yıllarda pseudoalkolik karaciğer hastalığı, alkol bezeri hepatit, diyabetik hepatit, non alkolik Laennec hastalığı ve steatonekroz gibi terimler kullanılagelmiştir (2). Her ne kadar, 1980'ler öncesinde yapılan çalışmalar, obez hastalarda bariatrik cerrahi öncesi ve sonrası biyopsilerde hepatik steatozisi dökümante etse de, (6) ilk kez, 1980 yılında Ludwig ve arkadaşları tarafından alkol kullanım öyküsü olmayan 20 hastada steatozis, inflamatuvar infiltratlar, mallory cisimciği, fibrozis ve sirozu içeren histolojik değişikliklerin tanımlandığı "NASH" kavramı rapor edilmiştir (7). Yapılan klinik ve histopatolojik çalışmalar, basit yağlanmanın düşük olasılıkla ileri karaciğer hastalığına progrese olduğunu göstermiş olmakla beraber, NASH'li olgular siroz, son dönem karaciğer yetmezliği ve olasılıkla hepatosellüler kanser açısından yüksek risk altındadırlar $(8,9)$. Sirotik NASH hastalarının 5 ve 10 yıl sağkalımları sırasıyla yaklaşık \%67 ve \%59 olarak tahmin edilmektedir ve karaciğer nakli nedenlerinden biridir (10-12). NAYKH en sık obezite, diyabetes mellitus (DM), dislipidemi ve insülin direnci gibi metabolik sendrom komponentleriyle ilişkilidir (13-18). NAYKH'de risk faktörleri kısmen tanımlanmış olsa da, ne yazık ki, NAYKH'dan NASH'e ve ileri evre fibrozis progresyonuna etki eden faktörler hala açık değildir. Bu çalışmada, NAYKH'da uzun dönemde karaciğerdeki histolojik değişikliklerin incelenmesi, histolojik değişikliklerle ilişkili klinik ve laboratuvar parametrelerin araştıııması amaçlanmıştır.

\section{GEREÇ ve YÖNTEM}

\section{Hasta Seçimi}

Ege Üniversitesi Tıp Fakültesi Gastroenteroloji Bilim Dalı Hepatoloji Polikliniği'ne 1994-2009 yılları arasında ayaktan başvuran, karaciğer biyopsisi yapılarak NAYKH tanısı almış, hepatoloji veri tabanına kayıtlı toplam 783 olgu taranmıştır. Hastalara ait veriler dosya bilgileri taranarak retrospektif olarak değerlendirilmiştir. Alkol kullanım öyküsü, geçirilmiş gastrointestinal sistem cerrahisi, karaciğer yağlanmasına sebep olabilecek ilaç kullanım öyküsü ya da ilaca bağlı karaciğer hastalığı olan, rutin tetkiklerinde hepatit $B, C$, otoimmün hepatit, primer biliyer siroz tanısı ve histopatolojik bulguları NAYKH'na ek olarak başka karaciğer hastalığı düşündüren olgular çalışma dışı bırakılmıştır. Böylelikle ek karaciğer hastalığı olan 103, ek karaciğer hastalığı olmayan ancak tek biyopsili 618 , çift karaciğer biyopsili ancak iki biyopsi arası zaman $<2$ yıl olan 27 ve iki biyopsi arası zaman $\geq 2$ yll olan ancak verileri yetersiz 6 olgu olmak üzere toplam 754 olgu dışlanmıştır. Çalışmaya, $\geq 2$ yıl ara ile çift karaciğer biyopsisi yapılmış, ek karaciğer hastalık öyküsü ya da tanısı olmayan 29 olgu dahil edilmiştir. Hastaların, NAYKH için almış oldukları tedaviler düzensiz olduğu için göz ardı edilmiştir. Ancak diayabeti olan hastalar kan şekeri regülasyonu için gerekli oral antidiayabetik veya insülin tedavisini almışlardır.

\section{Laboratuvar Verileri}

Biyopsi tarihinden 1 hafta önce ya da sonra kaydedilmiş klinik ve laboratuvar veriler, biyopsi sırasındaki veriler olarak kullanılmışır. Birinci ve ikinci biyopsi sırasında hastalara ait boy, kilo, vücut kitle indeksi (VKi), açlık kan şekeri (AKŞ), aspartat aminotransferaz (AST), alanin aminotransferaz (ALT), alkalen fosfataz (ALP), gama glutamil transferaz (GGT), total bilirübin, albümin, total kolesterol, trigliserid (TG), yüksek dansiteli lipoprotein (HDL), düşük dansiteli lipoprotein (LDL), trombosit, international normalized ratio (INR) ve HOMA-IR değerleri kaydedilmiştir.

Laboratuvar sonuçlarında; AKŞ: 60-110 mg/dL, AST $\leq 35$ $\mathrm{IU} / \mathrm{L}, \mathrm{ALT} \leq 45 \mathrm{IU} / \mathrm{L}, \mathrm{ALP}:$ 40-129 IU/L, GGT $\leq 55 \mathrm{IU} / \mathrm{L}$, albümin: $3.5-5.2 \mathrm{~g} / \mathrm{dL}$, total bilirübin: 0.1-1 mg/dL, total kolesterol $<200 \mathrm{mg} / \mathrm{dL}$, TG $<150 \mathrm{mg} / \mathrm{dL}$, LDL-kolesterol $<130 \mathrm{mg} / \mathrm{dL}, \mathrm{HDL}-\mathrm{kolesterol}>55 \mathrm{mg} / \mathrm{dL}$, INR: 0.9-1.2, trombosit: $150-450 \mathrm{bin} / \mathrm{mm}^{3}$ değerleri normal olarak kabul edilmiştir.

\section{Tanımlamalar}

Diyabet tanısı, Amerikan Diyabet Cemiyeti DM tanı kriterlerine göre konulmuştur. Buna göre; AKŞ $<100$ mg/ dL normal, AKŞ: 100-125 mg/dL bozulmuş açlık glukozu (BAG), AKŞ $\geq 126 \mathrm{mg} / \mathrm{dL}$ (2 kez) DM olarak tanımlanmıştır. Oral glukoz tolerans testi (OGTT) yapılan olgularda; 2. saat kan şekeri $\leq 140 \mathrm{mg} / \mathrm{dL}$ normal, $140-199 \mathrm{mg} / \mathrm{dL}$ bozulmuş OGTT ve $\geq 200 \mathrm{mg} / \mathrm{dL}$ DM olarak sınıflanmıştır (19).

VKi'ne göre hastaların sınıflaması, VKi değerleri klavuzuna göre yapılmıştır. Buna göre hastalar; VKI; $<25 \mathrm{~kg} / \mathrm{m}^{2}$ zayıf, $25-29.9 \mathrm{~kg} / \mathrm{m}^{2}$ kilolu ve $\geq 30 \mathrm{~kg} / \mathrm{m}^{2}$ obez olarak 
tanımlanmıştır (20). Kilo farkı (kg)=[2. biyopsi anındaki kilo]-[1. biyopsi anındaki kilo] olarak hesaplanmıştır. Kilo farkl; > (+1) kg ise "kilo alan grup", \pm 1 kg ise "kilosu değişmeyen grup" ve $>(-1)$ kg ise "kilo veren grup" olarak sınıflanmıştır.

Olgularda insülin direncinin olup olmadığı, homeostasis assessment model (HOMA) indeksi (HOMA-IR) hesaplanarak değerlendirilmiştir. İnsülin direnci için $\mathrm{HOMA-IR=[Aç-}$ lık plazma insülin $(\mathrm{mU} / \mathrm{ml})$ ] $X$ [açlık plazma glukoz (mmol/L)]/22.5 şeklinde hesaplanmıştır (21). HOMA IR > 2.7 olanlar "insülin direnci" olarak kabul edilmiştir.

\section{Histopatolojik Değerlendirme ve Skorlama}

Hastaların tanı ve izlem amacı ile yapılmış olan formalin tespitli parafine gömülü karaciğer biyopsilerinden hazırlanan hematoksilen-eozin, Masson trikrom, retikulum boyaları ile boyanmış olan preparatları bir patolog tarafından tekrar değerlendirilmiştir. Lobüler nekroinflamasyon ve steatozis hematoksilen-eozin boyalı preparatlarda, fibrozis ve yapısal değişiklikler Masson trikrom ve retikulum boyalarda değerlendirilmiş ve yeniden skorlanmıştır. Histopatolojik skorlama Kleiner ve ark.'nın geliştirdiği skorlama sistemine göre yapılmıştır (Tablo 1) (22). Bu histopatolojik skorlama sistemi 14 histolojik özellik içermektedir, bunlardan 4 histolojik özellik semi-kantitatif; steatozis (0-3), lobüler inflamasyon (0-3), hepatosit balonlaşması (0-2) ve fibrozis (0-4), geri kalan 9'u ise "var" yada "yok" şeklinde kalitatif olarak değerlendirilmiştir. Nonalkolik yağlı karaciğer hastalığı aktivite skoru (NAS); steatozis, lobüler inflamasyon ve hepatosit balonlaşması skorlarının toplamından oluşmuştur. Toplam skor 0-8 arasındadir. NAS skoru $\geq 5$ ise "kesin NASH", NAS skoru=3 ve 4 "olası NASH", NAS skoru < 3 ise "NASH'le uyumlu değil" şeklinde değerlendirilmiştir. NAS skoru, fibrozisi içermediğinden, fibrozis ayrıca Kleiner ve arkadaşlarının yayınında belirtildiği şekilde değerlendirilmiştir (22). Fibrozis skoru 0-4 arasında olup, skor 0 "fibrozis bulgusu yok", skor 4 ise "siroz" olarak tanımlanmışıı. NAS skorunu etkileyen parametreler ve fibrozis skorlaması Tablo 2'de verilmiştir.

Hastalara ait 1. ve 2. biyopsi NAS değerleri hesaplanmış, nekroinflamatuvar aktivite progresyonu açısından iki biyopsi arası NAS farkı elde edilmiştir.

NAS skoru farkı=[2. biyopsi NAS değeri]-[1 1 biyopsi NAS değeri] olarak hesaplanmıştır. NAS farkı açısından hastalar; NAS farkı > 0 olan grup, "NAS kötüleşen" ve $\leq 0$ olan grup, "NAS ilerlemeyen" olarak iki gruba ayrılmıştır.

Aynı şeklide, fibrozis farkı=[2. biyopsi fibrozis skoru]-[1. biyopsi fibrozis skoru] formülüyle hesaplanarak, fibrozis farkl; > 0 olan grup "fibrozisi kötüleşen" ve $\leq 0$ olan grup "fibrozis ilerlemeyen" olarak iki gruba ayrılmıştır.

Istatistiksel analizler SPSS programı kullanılarak; ki-kare, student $t$ (bağımlı ve bağımsız), Mann Whitney $U$ ve spearman korelasyon testi kullanılarak yapılmıştır, $p$ değeri < 0.05 anlamlı kabul edilmiştir.

Bu çalışma için Ege Üniversitesi Tıp Fakültesi Klinik Araştırmalar Etik Komitesinden etik kurul onayı (tarih: 07.10.2010, sayı:10-8/17) alınmıştır.

\section{BULGULAR}

Çalışmaya alınan 29 hastanın başlangıç biyopside ortalama yaşı 45.2 \pm 11 olup, 29 hastanın 17'si erkek (\%58.6), 12 'si kadındır (\%41.4). Birinci ve ikinci biyopsiler arasında geçen ortalama süre 4.8 2 yıl (2-9) olarak hesaplanmıştır. AST yüksekliği, 1. ve 2. biyopsi anında sırasıyla, olguların 22 'sinde (\%75.9) ve 16 'sında (\%55.2) saptanmıştır. ALT yüksekliği, 1. ve 2. biyopside sırasıyla, olguların 22 'sinde (\%75.9) ve 20'sinde (\%69) saptanmıştır. AST/ALT oranı hem 1., hem 2. biyopside 25 hastada $(\% 86.3)<1$ bulunmuştur. HOMA-IR skor verisi mevcut 15 hastanın 9'unda (\%60) insülin direnci saptanmıştır. Birinci ve 2. biyopsi anında hastalara ait özellikler Tablo 3'de gösterilmiştir. Birinci ve 2. biyopsi verileri karşılaştıııldığında; ortalama kilo, VKI, AKŞ, AST, ALT, GGT, total bilirübin, albümin, trombosit, INR, total kolesterol, TG, LDL, HDL değerleri arasında istatistiksel olarak anlamlı fark saptanmazken ( $p$ $>0.05$ ), ortalama ALP arasında istatistiksel olarak anlamlı farklılık saptanmıştır $(p=0.01)$ (Tablo 3 ).

Hastaların AKŞ düzeylerine göre; 1. biyopside 10 hastada (\%34.5), 2. biyopside 12'sinde (\%41.4) AKŞ $\geq 110 \mathrm{mg} /$ dL saptanmıştır. AKŞ düzeyleri ve OGTT sonuçlarına göre 1. biyopsi sırasında; hastaların 12'sinde (\%41.4) DM yok, 11 'inde (\%37.9) DM, 6'sında (\%20.7) bozulmuş OGTT ve 2. biyopsi sırasında; hastaların 9'unda (\%31) DM yok, 13'ünde (\%44.8) DM, 7'sinde (\%24.1) bozulmuş OGTT saptanmıştır (Şekil 1).

Hiperglisemisi olan (DM+bozulmuş OGTT) ve olmayan gruplar karşılaştııılı̆ğında birinci biyopsi NAS skoru, ikinci biyopsi NAS ve fibrozis skoru ortalamaları arasında istatistiksel olarak anlamlı fark saptanmıştır (Tablo 4). NAS ve fibrozis skoru farkı ortalamalarında, birinci ve ikinci biyopsi sırasında, iki grup arasında istatistiksel olarak anlamlı fark saptanmamıştır $(p>0.05)$.

Lipid parametrelerinden herhangi birinde bozukluk saptanan hasta sayısı 1. biyopside; 22 (\%76), 2. biyopside 24 (\%82) bulunmuştur. 
ÜNAL ve ark.

Tablo 1. Nonalkolik karaciğer yağlanması klinik araştırma ağı skorlama sistemi tanımları ve skorları (22)

\begin{tabular}{|c|c|c|}
\hline & Tanım & Sko \\
\hline \multicolumn{3}{|l|}{ Steatozis } \\
\hline \multirow[t]{4}{*}{ Derece } & $<\% 5$ & 0 \\
\hline & $\% 5-\% 33$ & 1 \\
\hline & $\% 33-\% 66$ & 2 \\
\hline & $>\% 66$ & 3 \\
\hline \multirow[t]{4}{*}{ Lokalizasyon } & Zone 3 & 0 \\
\hline & Zone 1 & 1 \\
\hline & Azonal & 2 \\
\hline & Panasiner & 3 \\
\hline \multirow[t]{2}{*}{ Mikroveziküler yağlanma } & Yok & 0 \\
\hline & Var & 1 \\
\hline
\end{tabular}

\section{Fibrozis}

Evre

Yok

0

Perisinüzoidal veya periportal

Hafif, zone 3 perisinüzoidal

1

Ilımlı, zone 3 perisinüzoidal

Portal / periportal

Perisinüzoidal ve portal / periportal 2

Köprüleşme fibrozisi 3

Siroz $\quad 4$

\section{İnflamasyon}

\begin{tabular}{|c|c|c|}
\hline \multirow[t]{4}{*}{ Lobüler inflamasyon } & Odak yok & 0 \\
\hline & $<2$ odak her $\times 200$ alan & 1 \\
\hline & 2-4 odak her $\times 200$ alan & 2 \\
\hline & $>4$ odak her $\times 200$ alan & 3 \\
\hline \multirow[t]{2}{*}{ Mikrogranülomlar } & Yok & 0 \\
\hline & Var & 1 \\
\hline \multirow[t]{2}{*}{ Geniş lipogranülomlar } & Var & 0 \\
\hline & Yok & 1 \\
\hline \multirow[t]{2}{*}{ Portal inflamasyon } & Yok ya da minimal & 0 \\
\hline & Minimalden fazla & 1 \\
\hline \multicolumn{3}{|l|}{ Karaciğer hücre hasarı } \\
\hline \multirow{3}{*}{ Balonlaşma } & Yok & 0 \\
\hline & Az balon hücre & 1 \\
\hline & Çok balon hücre & 2 \\
\hline \multirow[t]{2}{*}{ Asidofil cisim } & Yok ya da seyrek & 0 \\
\hline & Çok & 1 \\
\hline \multirow[t]{2}{*}{ Pigmentli makrofajlar } & Yok ya da seyrek & 0 \\
\hline & Çok & 1 \\
\hline \multirow[t]{2}{*}{ Megamitokondriler } & Yok ya da seyrek & 0 \\
\hline & Çok & 1 \\
\hline \multicolumn{3}{|l|}{ Diğer bulgular } \\
\hline \multirow[t]{2}{*}{ Mallory hiyalin } & Yok ya da seyrek & 0 \\
\hline & Çok & 1 \\
\hline \multirow[t]{2}{*}{ Glikojen nüve } & Yok ya da seyrek & 0 \\
\hline & Çok & 1 \\
\hline
\end{tabular}


Tablo 2. Nonalkolik karaciğer yağlanması aktivite skorunu oluşturan komponentler ve fibrozis (22)

\begin{tabular}{|c|c|c|}
\hline & Tanım & Skor \\
\hline \multirow[t]{4}{*}{ Steatozis (derece) } & $<\% 5$ & 0 \\
\hline & $\% 5-\% 33$ & 1 \\
\hline & $\% 33-\% 66$ & 2 \\
\hline & $>\% 66$ & 3 \\
\hline \multirow[t]{4}{*}{ Lobüler inflamasyon } & Odak yok & 0 \\
\hline & $<2$ odak her $\times 200$ alan & 1 \\
\hline & 2-4 odak her $X 200$ alan & 2 \\
\hline & $>4$ odak her $\times 200$ alan & 3 \\
\hline \multirow[t]{3}{*}{ Balonlaşma } & Yok & 0 \\
\hline & Az balon hücre & 1 \\
\hline & Çok balon hücre & 2 \\
\hline \multirow[t]{8}{*}{ Fibrozis (evre) } & Yok & 0 \\
\hline & Perisinüzoidal veya periportal & 1 \\
\hline & Hafif, zone 3 perisinüzoidal & $1 \mathrm{~A}$ \\
\hline & Ilımlı, zone 3 perisinüzoidal & $1 \mathrm{~B}$ \\
\hline & Portal / periportal & $1 C$ \\
\hline & Perisinüzoidal ve portal / periportal & 2 \\
\hline & Köprüleşme fibrozisi & 3 \\
\hline & Siroz & 4 \\
\hline
\end{tabular}

Tablo 3. Nonalkolik yağlı karaciğer hastalarına ait birinci ve ikinci biyopsi anındaki veriler ve ortalamalarının karşılaştırılması

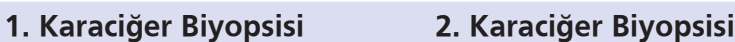

$\mathrm{n}=\mathbf{2 9}$

Ortalama \pm SD (min-max)

p değeri

\begin{tabular}{|c|c|c|c|}
\hline Yaş (yıl) & $45.2 \pm 11(22-70)$ & $50 \pm 11.7(26-78)$ & \\
\hline Boy $(\mathrm{cm})$ & $164.1 \pm 10(147-179)$ & & \\
\hline Kilo (kg) & $79.9 \pm 15(60-110)$ & $79.8 \pm 14.3(60-122)$ & 0.9 \\
\hline VKi $\left(\mathrm{kg} / \mathrm{m}^{2}\right)$ & $29.5 \pm 3.9(22-38)$ & $29.6 \pm 4.1(22-42)$ & 0.7 \\
\hline AKŞ (mg/dL) & $109.7 \pm 35.8(60-231)$ & $119.6 \pm 36.7(80-257)$ & 0.3 \\
\hline Serum AST (IU/L) & $50.5 \pm 35.8(13-177)$ & $38.8 \pm 14.4(18-75)$ & 0.07 \\
\hline Serum ALT (IU/L) & $79.4 \pm 49.7(12-195)$ & $59.2 \pm 31.7(16-153)$ & 0.07 \\
\hline AST/ALT & $0.74 \pm 0.3(0.3-1.8)$ & $0.76 \pm 0.3(0.3-1.8)$ & 0.8 \\
\hline Serum ALP (IU/L) & $215.4 \pm 97.4(76-506)$ & $158.3 \pm 72(74-433)$ & 0.01 \\
\hline Serum GGT (IU/L) & $54.7 \pm 50.4(13-202)$ & $57 \pm 55.5(15-295)$ & 0.9 \\
\hline Serum total bilirübin $(\mathrm{mg} / \mathrm{dL})$ & $0.6 \pm 0.3(0.2-1.4)$ & $0.9 \pm 0.9(0.3-5.6)$ & 0.1 \\
\hline Serum albümin (g/dL) & $4.5 \pm 0.4(3.4-5.1)$ & $4.5 \pm 0.5(2.7-5)$ & 0.9 \\
\hline Kan trombosit $\left(\times 1000 / \mathrm{mm}^{3}\right)$ & $231.2 \pm 68.1(54-397)$ & $242.1 \pm 69.9(27-397)$ & 0.5 \\
\hline INR & $0.9 \pm 0.1(0.7-1.2)$ & $1 \pm 0.1(0.7-1.2)$ & 0.9 \\
\hline Serum total kolesterol (mg/dL) & $213.6 \pm 48.6(116-327)$ & $218.4 \pm 55.8(110-327)$ & 0.7 \\
\hline Serum trigliserid (mg/dL) & $197.4 \pm 106.3(52-442)$ & $187.5 \pm 79.8(56-429)$ & 0.7 \\
\hline Serum LDL (mg/dL) & $132.8 \pm 35.7(52-214)$ & $138.5 \pm 43.3(49-230)$ & 0.6 \\
\hline Serum HDL (mg/dL) & $46.5 \pm 9.9(30-67)$ & $48.6 \pm 12.7(31-89)$ & 0.5 \\
\hline NAS & $4 \pm 1.8(0-7)$ & $3.5 \pm 2(0-7)$ & 0.3 \\
\hline Fibrozis skoru & $1 \pm 1.2(0-4)$ & $1.1 \pm 1.3(0-4)$ & 0.5 \\
\hline
\end{tabular}

SD: Standart sapma; VKI: Vücut kitle indeksi; AKŞ: Açlık kan şekeri; AST: Aspartat aminotransferaz; ALT: Alanin aminotransferaz; ALP: Alkalen fosfataz; GGT: Gama glutamil transferaz; HDL: Yüksek dansiteli lipoprotein; LDL: Düşük dansiteli lipoprotein; INR: International normalized ratio; NAS: Nonalkolik yağlı karaciğer hastalığı aktivite skoru. 


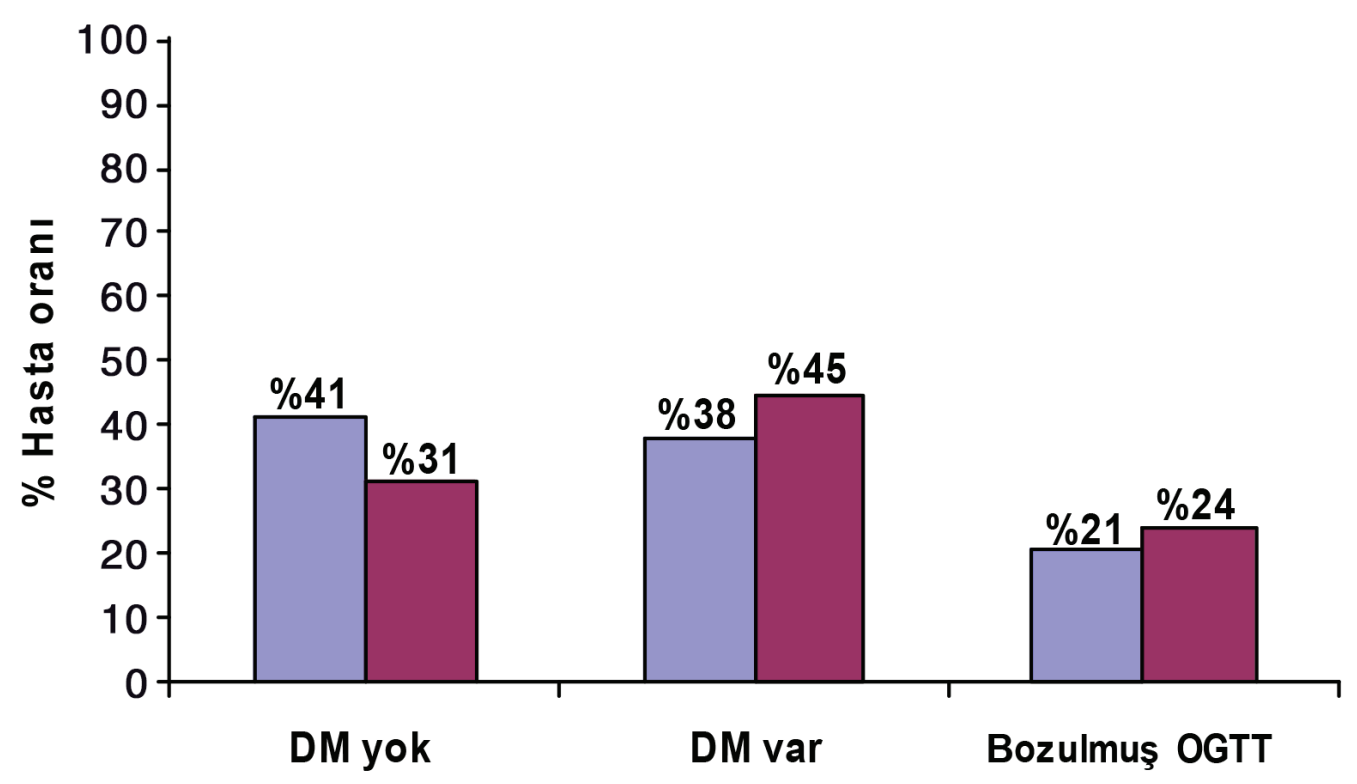

Şekil 1. Nonalkolik yağlı karaciğer hastalığında glisemik durum açısından dağılım.

DM: Diabetes mellitus; OGTT: Oral glukoz tolerans testi.

Tablo 4. Hiperglisemisi olan ve olmayan gruplar arasında NAS ve fibrozis skoru ortalamaları karşılaştırması

\begin{tabular}{|lcccc} 
& Hiperglisemisi Olmayan Grup & Hiperglisemisi Olan Grup & u & $\mathbf{p}$ \\
\hline 1. Biyopsi & $(n=12)$ & $(n=17)$ & 55.5 & $\mathbf{0 . 0 3}$ \\
\hline NAS skoru & $3 \pm 2$ & $4.6 \pm 1.3$ & 61 & 0.055 \\
\hline Fibrozis skoru & $0.6 \pm 1$ & $1.4 \pm 1.2$ & & \\
\hline 2. Biyopsi & $(n=9)$ & $(n=20)$ & 41.5 & $\mathbf{0 . 0 2}$ \\
\hline NAS skoru & $2.1 \pm 1.9$ & $4 \pm 1.7$ & 27.5 & $\mathbf{0 . 0 0 2}$
\end{tabular}

NAS: Nonalkolik yağlı karaciğer hastalığı aktivite skoru.

VKi değerlerine göre, 1. biyopside; 29 hastanın 2'si (\%6.9) normal, 15'i (\%51.7) kilolu, 12'si (\%41.4) obez ve 2. biyopside; 2'si (\%6.9) normal, 17'si (\%58.6) kilolu, 10'u obez (\%34.5) bulunmuştur. İki biyopsi arası kilo farkının dağılımı Şekil 2'de gösterilmiştir. Hastalar normal ve kilolu+obez olmak üzere iki gruba ayrıldığında gruplar arasında, 1. ve 2. biyopsi NAS ve fibrozis skoru ortalamaları açısından istatistiksel olarak anlamlı farklılık saptanmamıştır (sırasıyla; $u=26.5 \mathrm{p}=0.96, \mathrm{u}=23.5 \mathrm{p}=0.75$, $u=21 p=0.6, u=20.5 p=0.55$ ). Kilo alan, veren ve kilosu değişmeyen gruplar arasında NAS ve fibrozis skoru farkı açısından istatistiksel olarak anlamlı fark saptanmamıştır $\left(x^{2} k w=1.68 p=0.43\right.$ ve $\left.x^{2} k w=4.7 p=0.09\right)$.
Hastalara ait 1. ve 2. biyopsideki histopatolojik skorlama sonuçları Tablo 5'de ve hastalara ait histopatolojik bulgular, Şekil 3'de gösterilmiştir.

Birinci biyopside histopatolojik olarak "kesin NASH" tanIsI alan 14 hastadan, 2. biyopside 8'i "kesin NASH", 4'ü "olası NASH" ve 2'si "NASH'le uyumlu değil" olarak değerlendirilmiştir. Birinci biyopside "olası NASH" tanısı alan 9 hastadan, 2. biyopside 2'si "kesin NASH", 5'i "olası NASH" ve 2'si "NASH'le uyumlu değil" tanısı almıştır. Birinci biyopside basit yağlanması olan "NASH değil" grubundaki 6 hastadan, 2. biyopside 3'ü "olası NASH" ve 3'ü "NASH'le uyumlu değil" olarak tanımlanmıştır (Şekil 4). 


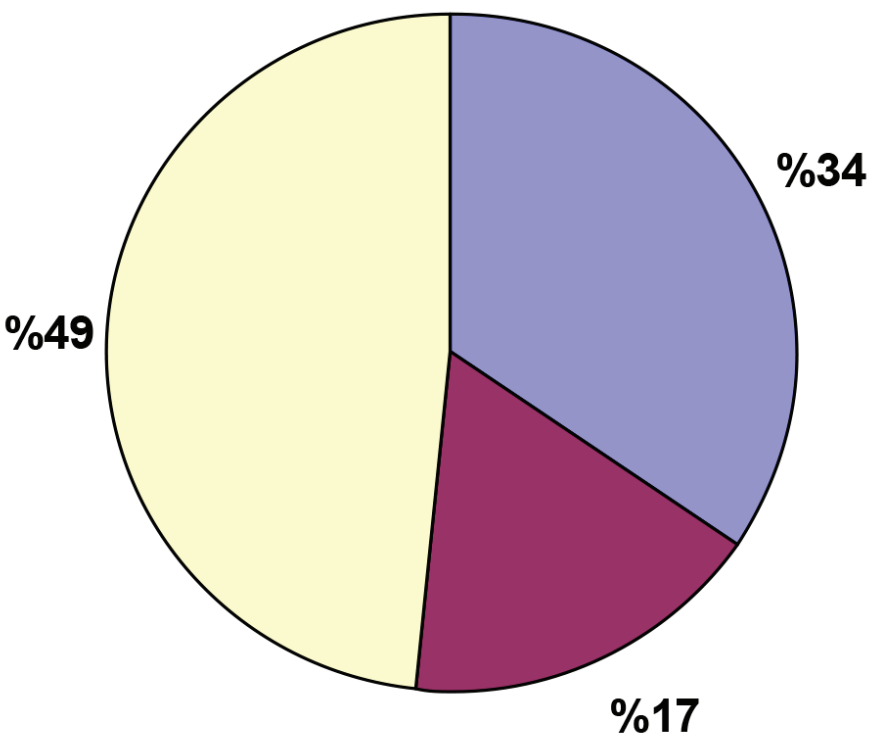

$\square \mathrm{kg}$ veren $(n=10)$

$\square \mathrm{kg}$ aynı $(n=5)$

$\square \mathrm{kg}$ alan $(n=14)$

Şekil 2. Nonalkolik yağlı karaciğer hastalarında biyopsiler arasında kilo değişim grafiği.

A
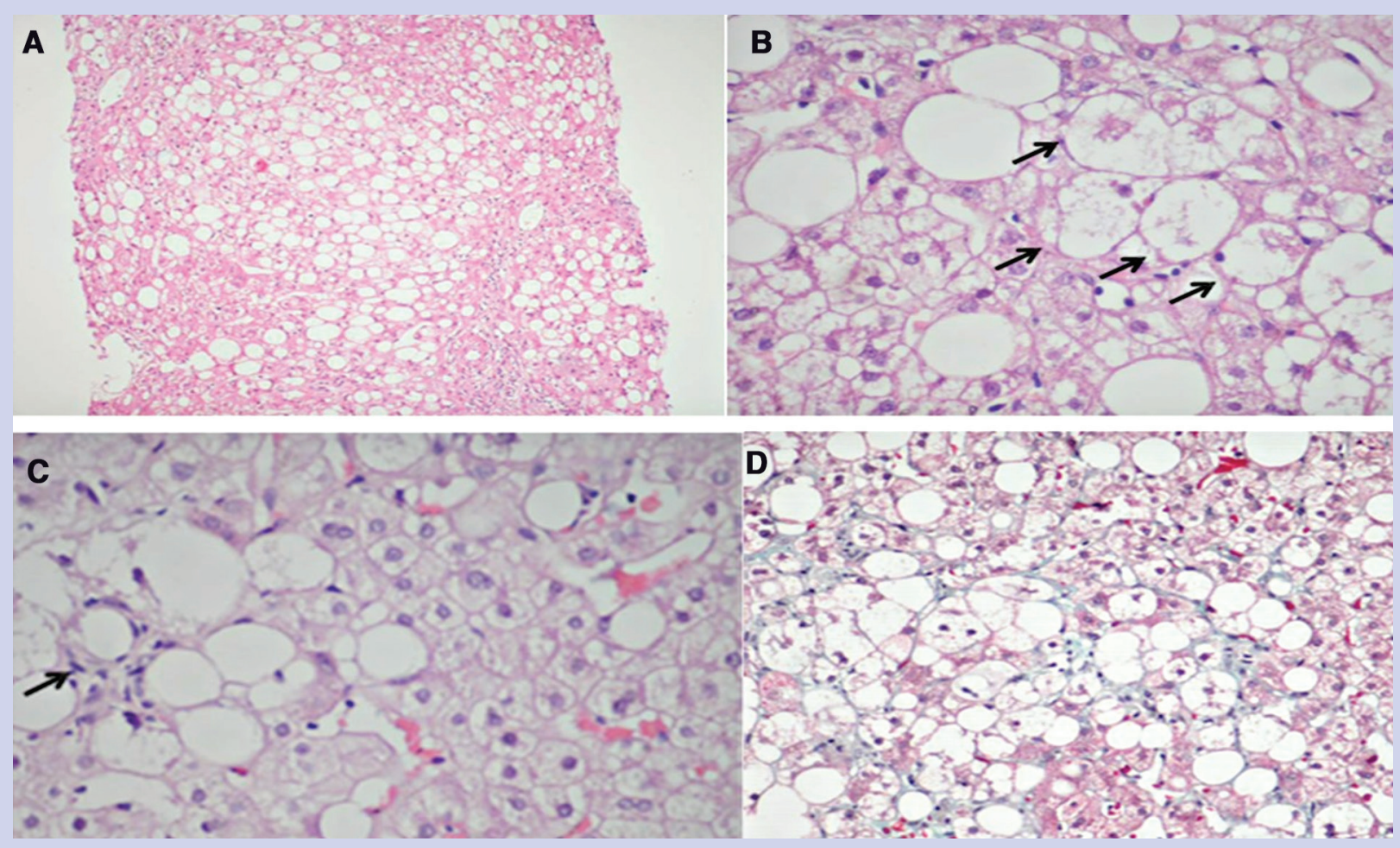

Şekil 3. (A) NAS skorunda değerlendirilen komponentlerden steatozis (HE, x100), (B) hepatosit balonlaşması (oklar) (HE, x400), (C) lobüler inflamasyon (ok) (HE, x200) ve (D) balonlaşmış hepatositler çevresinde perisellüler fibrozis (oklar) (Masson trikrom, x100). (Ege Üniversitesi Tıp Fakültesi Patoloji Anabilim Dalı Arşivinden alınmıştır.) 


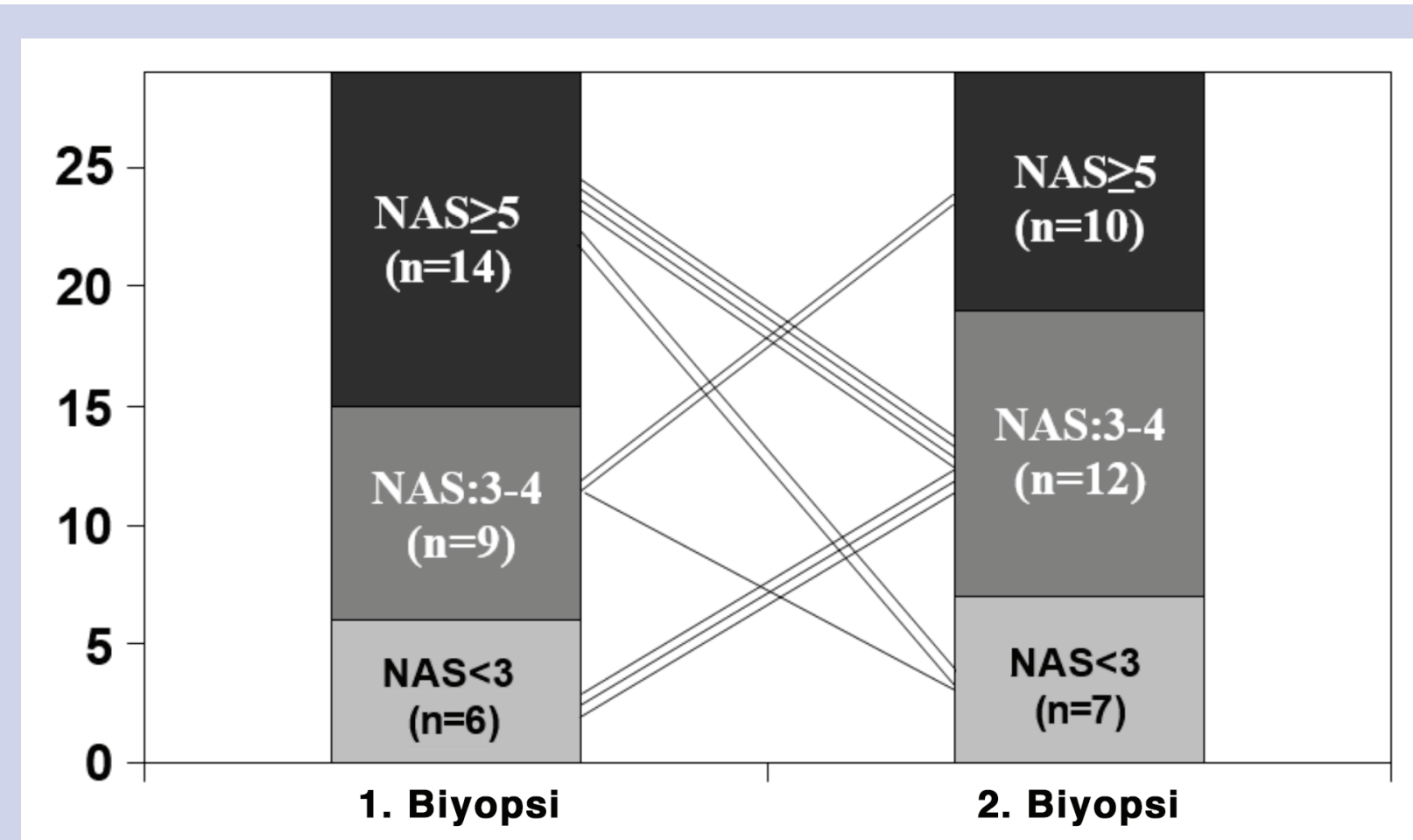

Şekil 4. Non-alkolik yağlı karaciğer hastalığı aktivite skorlarının dağılımı.

NAS: Nonalkolik yağı karaciğer hastalığı aktivite skoru.

Tablo 5. Nonalkolik yağlı karaciğer hastalığında 1. ve 2. biyopsilerde histopatolojik skor dağılımı

\begin{tabular}{|ccc|}
\hline & 1. Biyopsi & 2. Biyopsi \\
\hline Makroveziküler steatozis & $\mathbf{n}(\%)$ & $\mathbf{n}(\%)$ \\
\hline Grade 0 & $4(13.8)$ & $5(17.2)$ \\
\hline Grade 1 & $11(37.9)$ & $12(41.4)$ \\
\hline Grade 2 & $10(34.5)$ & $9(31)$ \\
\hline Grade 3 & $4(13.8)$ & $3(10.3)$ \\
\hline Lobüler inflamasyon & & \\
\hline Grade 0 & $7(24.1)$ & $8(27.6)$ \\
\hline Grade 1 & $13(44.8)$ & $13(44.8)$ \\
\hline Grade 2 & $5(17.2)$ & $6(20.7)$ \\
\hline Grade 3 & $4(13.8)$ & $2(6.9)$ \\
\hline Balonlaşma & & \\
\hline Grade 0 & $4(13.8)$ & $5(17.2)$ \\
\hline Grade 1 & $12(41.4)$ & $16(55.2)$ \\
\hline Grade 2 & $13(44.8)$ & $8(27.6)$ \\
\hline
\end{tabular}

Birinci biyopside fibrozis saptanmayan "evre 0" 13 hastanın, ikinci biyopside 9'unun "evre 0" devam ettiği, 2'sinin "evre 1" ve 2'sinin "evre 4" yani siroza ilerlediği görülmüştür. Birinci biyopside fibrozis "evre 1" saptanan 7 hastada ikinci biyopside 3'ü "evre 0", 1'i "evre 1", 3'ü "evre
2" ve 1 'i "evre 3 " saptanmıştır. Birinci biyopside fibrozis "evre 2" olan 4 hastanın 1'i "evre 1" olmuş, 3'ü "evre 2" olarak devam etmiş, birinci biyopside fibrozisi "evre 3" olan 4 hastanın 2'si ikinci biyopside "evre 3", 2'si "evre 1" saptanmıştır. Birinci biyopside "evre 4" siroz saptanan 1 hastada ise ikinci biyopside fibrozis "evre 0" saptanmıştır. Birinci ve 2. biyopsilerde fibrozis skorlarının dağılımı Şekil 5'de verilmiştir.

Tablo 6 . Birinci ve 2 . biyopsilerde nonalkolik yağlı karaciğer hastalığı aktivite skorları

\begin{tabular}{|ccc|}
\hline NAS & 1. Biyopsi & 2. Biyopsi \\
\hline 0 & $\mathbf{n}(\%)$ & $\mathbf{n}(\%)$ \\
\hline 1 & $1(\% 3.4)$ & $3(\% 10.3)$ \\
\hline 2 & $2(\% 6.9)$ & $3(\% 10.3)$ \\
\hline 3 & $3(\% 10.3)$ & $1(\% 3.4)$ \\
\hline 4 & $6(\% 20.7)$ & $8(\% 27.6)$ \\
\hline 5 & $3(\% 10.3)$ & $4(\% 13.8)$ \\
\hline 6 & $7(\% 24.1)$ & $5(\% 17.2)$ \\
\hline 7 & $6(\% 20.7)$ & $3(\% 10.3)$ \\
\hline 8 & $1(\% 3.4)$ & $2(\% 6.9)$ \\
\hline
\end{tabular}

NAS: Nonalkolik yağlı karaciğer hastalığı aktivite skoru. 


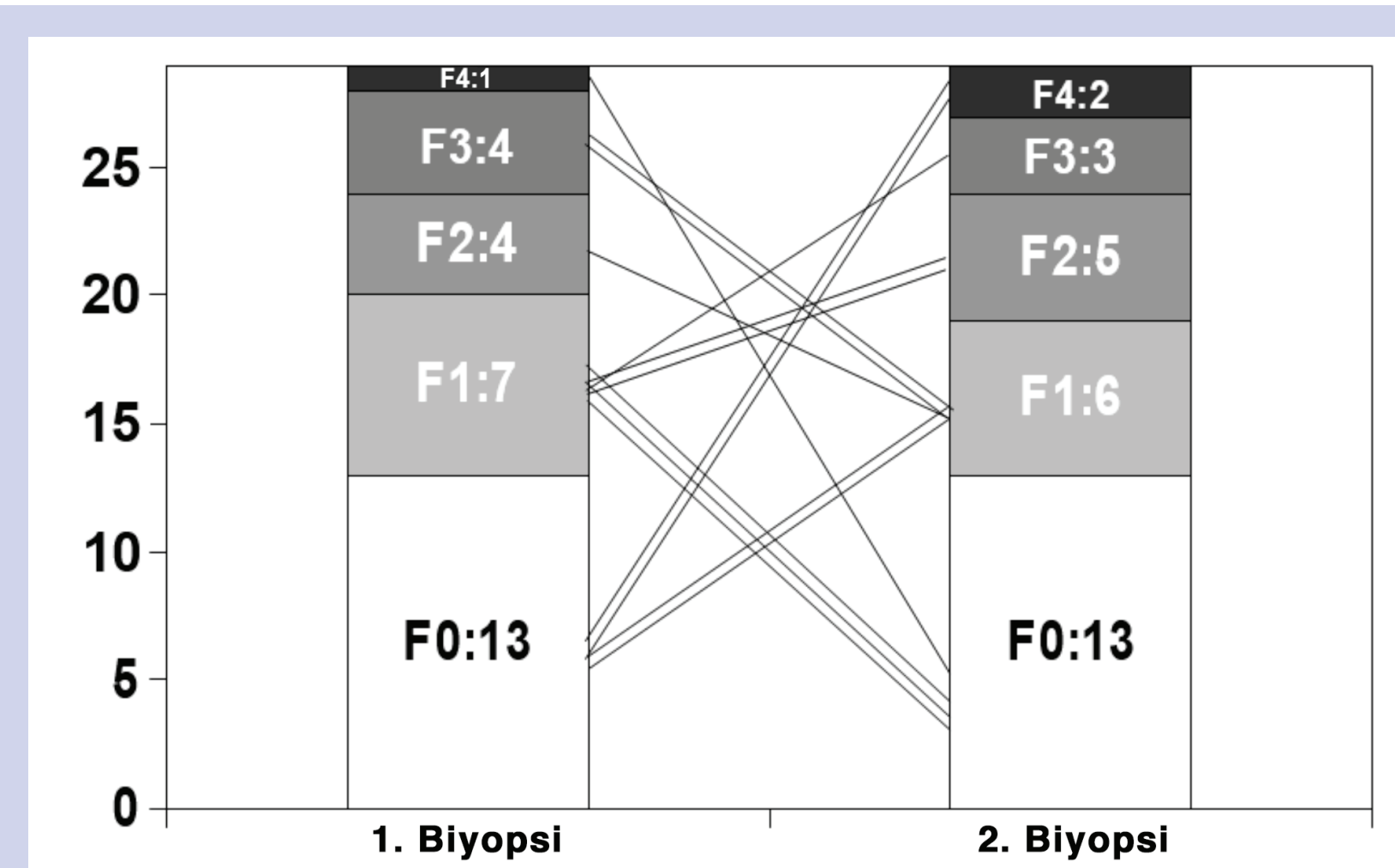

Şekil 5. Birinci ve 2. biyopsilerdeki fibrozis skorlarının dağlımı.

Birinci ve ikinci biyopsilerde NAS ve fibrozis skorlarının dağılımı, hasta sayı ve yüzdeleri Tablo 6 ve 7'de gösterilmiştir.

Çalışmaya alınan 29 hastanın, ikinci biyopsi sırasında ALT düzeyleri normal olan 9'unda (\%31) fibrozis skorunun progresyon göstermediği görülmüştür. 19 (\%65.5) hastada, hem NAS hem de fibrozis skorları ilerleme göstermezken, 6 (\%20) hastada, hem NAS hem de fibrozis

Tablo 7. Birinci ve 2. biyopsilerde fibrozis skorları ve dağılımı

\begin{tabular}{|c|c|c|}
\hline Fibrozis Skoru & 1. Biyopsi & 2. Biyopsi \\
\hline & n (\%) & n (\%) \\
\hline 0 & $13(\% 44.8)$ & $13(\% 44.8)$ \\
\hline 1 & $5(\% 17.2)$ & $3(\% 10.3)$ \\
\hline $1 \mathrm{~A}$ & $1(\% 3.4)$ & $2(\% 6.9)$ \\
\hline $1 B$ & - & - \\
\hline $1 \mathrm{C}$ & $1(\% 3.4)$ & $1(\% 3.4)$ \\
\hline 2 & $4(\% 13.8)$ & $5(\% 17.2)$ \\
\hline 3 & 4 (\%13.8) & $3(\% 10.3)$ \\
\hline 4 & $1(\% 3.4)$ & $2(\% 6.9)$ \\
\hline
\end{tabular}

skorlarının progresyon gösterdiği saptanmıştır. 3 (\%10) hastada NAS skoru progrese olurken fibrozis skoru progresyon göstermemiştir, 1 (\%0.03) hastada ise fibrozis skoru progresyon gösterirken NAS skoru progresyon göstermemiştir.

NAS skoru farkı değerlendirildiğinde; 29 hastanın 17'sinde (\%58.7) skorun iyileştiği, 3'ünde (\%10.3) aynı kaldığı ve 9'unda (\%31) kötüleştiği saptanmıştır. Fibrozis skoru farkı değerlendirildiğinde; 7 hastanın (\%24.2) skorunun iyileştiği, 15'inin (\%51.7) aynı kaldığı ve 7'sinde (\%24.1) kötüleştiği bulunmuştur. NAS ve fibrozis skoru farklarına göre histopatolojik skoru "kötüleşen" ve "ilerlemeyen" gruplar Şekil 6'da gösterilmiştir.

NAS ve fibrozis skoru ilerlemeyen ve kötüleşen gruplar arasında biyopsiler arası geçen zaman karşılaştırılması Tablo 8'de verilmiştir.

Fibrozis skoru kötüleşen ve ilerlemeyen gruplar arasında NAS skoru farkına bakıldığında, fibrozisi ilerlemeyen grupta NAS skoru farkı $(-1) \pm 1.9$ ve kötüleşen grupta $1.3 \pm 1.6$ bulunmuştur. Bu fark istatistiksel olarak anlamlı bulunmuştur ( $p=0.016)$. Ayrıca fibrozis skoru kötüleşen 7 hastadan 6'sı (\%86) erkektir. Çalışma sonucunda NAS skoru ve fibrozis skoru farkı ile korelasyon gösteren parametreler Tablo 9'da verilmiştir. 


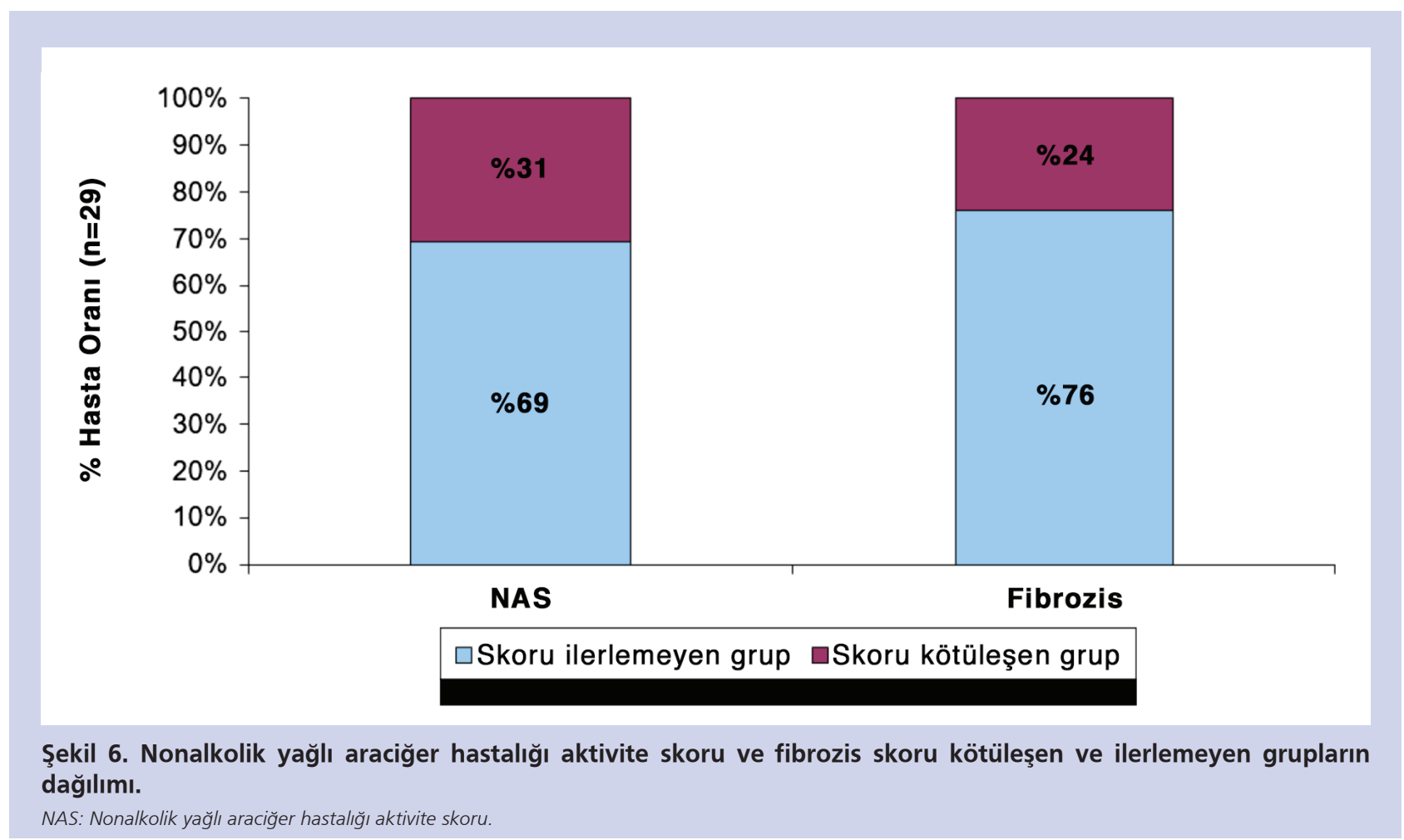

Tablo 8. NAS ve fibrozis skoru ilerlemeyen ve kötüleşen gruplar arasında biyopsiler arası geçen zaman ve karşılaştırılması

\begin{tabular}{llcc} 
& & İki Biyopsi Arası Geçen Zaman (yıl) & p Değeri \\
\multirow{2}{*}{ NAS skoru } & Ilerlemeyen grup $(n=20)$ & $4.6 \pm 2$ & 0.315 \\
& Kötüleşen grup $(n=9)$ & $5.4 \pm 2.2$ & 0.029
\end{tabular}

\section{Tablo 9. Nonalkolik yağlı karaciğer hastalığı aktivite skoru ve fibrozis skoru farkı ile ilişkili parametreler.}

$\begin{array}{lcccc}\mathbf{n}=\mathbf{2 9} & \text { Yaş } & \text { 1. Biyopside VKi } & \text { 2. Biyopside Vki } & \text { 2. Biyopside AST düzeyi } \\ \text { NAS skoru farkı } & \begin{array}{l}r=-0.370 \\ p=0.047\end{array} & p=0.485 & \\ & p=0.007 & r=0.409 & r=0.6 \\ \text { Fibrozis skoru fark' } & r=-0.503 & r=0.382 & p=0.027 & p=0.0005\end{array}$

VKI: Vücut kitle indeksi; AST: Aspartat aminotransferaz; NAS: Nonalkolik yağlı karaciğer hastalığı aktivite skoru.

\section{TARTIŞMA}

NAYKH, basit yağlanmadan, NASH ve siroza uzanan geniş bir spektrum göstermektedir. Bu çalışma sonucunda NAYKH tanısı almış hastaların \%31'inde NAS skorunun, \%24'ünde ise fibrozis skorunun progresyon gösterdiği saptanmıştır. En az bir yıl ara ile çift biyopsi yapılmış yaklaşık on çalışma ve 221 hastanın sonuçlarının değerlendi- rildiği bir çalışmada da hastaların yaklaşık \%37'sinde histolojik progresyon olduğu bildirilmiştir (23). Bu durum, sık histolojik örneklem güçlüğü gözönüne alındığında, NASH ve siroza ilerleyerek mortalite ve morbiditeye sebep olan NAYKH progresyonu ile ilişkili klinik ve laboratuvar değişkenlerinin belirlenmesindeki önemi vurgulamaktadır. 
Çalışmaya alınan ve 1. biyopside NAS skoruna göre "NASH değil" olarak tanımlanmış, basit yağlanması olan 6 hastanın hiçbirinde fibrozis saptanmamış olup, bu hastaların ortalama $4.2 \pm 1.7 \mathrm{yıl}$ ara ile yapılan ikinci biyopsilerinde de fibrozis gelişmediği görülmüştür. Bu bulgu, fibrozis olmaksızın sadece yağlanması olan olguların çok azının histolojik ve klinik progresyon gösterdiğini desteklemiştir $(8,9)$.

Fibrozis skoru ilerlemeyen grupta iki biyopsi arası geçen zaman ortalama 4.4 yıl, fibrozis skoru kötüleşen hasta grubunda ise biyopsiler arası geçen zaman ortalama 6.3 yıl bulunmuştur. İki grup arasındaki fark istatistiksel olarak anlamlıdır ( $p=0.029$ ). Bu bulgu NASH'te histolojik progresyonu göstermede ikinci biyopsi için acele edilmemesi gerektiğini ve en az 6 yıl ara ile yapılan ikinci biyopsinin fibrozis progresyonunu göstermede daha fikir verici olduğunu düşündürtmüştür.

Bu çalışma sonucunda, 25 (\%86) hastada NAYKH aktivite skoru ile fibrozis skorunun birlikte kötüleştiği ya da ilerlemediği görülmüştür, ayrıca fibrozis skoru kötüleşen grupta, NAS skorunun da kötüleştiği saptanmıştır. Bu bulgu, inflamasyonla fibrozisin yakın ilişkisinin doğal bir sonucu gibi görünse de, Argo ve ark.'nın başlangıç biyopsisinde nekroinflamasyonu olanların fibrozis progresyonu açısından daha yüksek riskli olduklarının altını çizdikleri çalışmada olduğu gibi, biyopside NAS skoru yüksek hastaların ileri fibrozis ve siroz gelişimi açısından yakın takibinin önemini hatırlatmıştır (23).

Sadece 4 olguda histolojik progresyon, NAS ve fibrozis skorunda zıt yönde bulunmuştur ancak bu durumun Merriman ve ark.'nın yaptıkları çalışmada vurguladıkları gibi, biyopsi örneklem değişkenliğinden de kaynaklanabileceği düşünülmüştür (24).

Kesitsel çalışmalarda DM varlığının, NAYKH'da, ilerlemiş karaciğer hastalığı için bir gösterge olduğu belirtilmiştir $(13,14)$. DM, fibrozis progresyonunda bağımsız bir risk faktörüdür. Bu çalışmada, DM ve bozulmuş oral glukoz tolerans testi olan hiperglisemik hastalarla, normoglisemik hastalar arasında 1. biyopsi NAS ve 2. biyopsi NAS ve fibrozis skorları arasında istatistiksel olarak fark saptanmıştır. Ancak bu iki grup arasında inflamasyon ve fibrozis progresyonu açısından istatistiksel olarak fark saptanmamıştır. Bu, hasta sayısının az olmasından kaynaklanabileceği gibi, hiperglisemik hastaların yakın glisemik takibi ve antidiyabetik tedavi hedeflerine iyi ulaşılması ile de açıklanabilir.

Yaş ile histolojik progresyon arasında zıt yönde orta düzeyde ilişki izlenmiş̧ir. Histolojik progresyonun göreceli olarak daha genç yaşlarda artış göstermesi, halen kesin bir tedavisi olmayan NAYKH'da, hastalığın ciddiyetini ve ileri fibrozisi belirlemede ilk biyopsiyi yapmakta çok geç kalınmaması gerektiğini telkin etmiştir. Fassio ve ark.'nın yaptıkları çalışmanın aksine, Argo ve ark.'nın sistematik analiz çalışmasında da, yaşın, ileri fibrozis progresyonunu göstermede, bağımsız bir risk faktörü olduğunun altı çizilmiştir $(23,25)$.

Çalısmaya alınan hasta grubunda erkek cinsiyetin \%59 oranında olmasına karşlık, fibrozis skoru kötüleşen 7 hastadan 6'sının (\%86) erkek olduğu görülmüştür. Erkeklerin kadınlara oranla histolojik progresyonda daha çok risk altında olduğu düşünülmüştür. Ancak bu bulgu, daha geniş çaplı çalışmalarla kanıtlanmalıdır zira bunu desteklemeyen çalışmalar da mevcuttur (25).

Nonalkolik yağlı karaciğer hastalığı ile obezite birlikteliğinin sık olduğu pek çok çalışma ile ortaya konmuştur (15-18). Çalışma sonucunda kilo alıp, vermenin histolojik progresyon üzerine etkisi saptanmazken, birinci ve ikinci biyopsi sırasındaki VKI ile fibrozis progresyonu arasında düşük düzeyde korelasyon mevcuttur, bu da kilo kontrolünün önemini vurgulamaktadır. Ancak son zamanlarda yapılan ve 1911 hastanın tarandı̆̆ı bir çalışmada NAY$\mathrm{KH}$ tanısı alanların \%75'inin VKi $<25 \mathrm{~kg} / \mathrm{m}^{2}$ olduğu ve NAYKH'nın çok daha geniş bir spektruma sahip olduğu gösterilmiştir (26).

Bazı çalışmalarda, aminotransferaz düzeyleri ile histolojik progresyon arasında ilişki saptanırken $(8,14)$, bazılarında aralarında ilişki izlenmemiştir $(23,25)$. Bizim çalışmamızın sonucuna göre, 2. biyopsi sırasında ALT düzeyi normal olan 9 (\%31) hastanın fibrozis skorunun progresyon göstermediği gözlenmiştir. İkinci biyopsi sırasındaki AST düzeyi ile fibrozis skoru farkı arasında da, pozitif yönde orta düzeyde korelasyon saptanmıştır ( $r=0.6$ ve $p=0.0005$ ). Bunun anlamı, 2. biyopsi esnasındaki AST düzeyindeki artışın fibrozis progresyonunun bir göstergesi olduğu ve özellikle AST düzeyi artış gösteren hastaların ileri fibrozis gelişimi açısından dikkatli takibinin gerektiğidir. Bu çaIışma sonucunu destekler nitelikte, Harrison ve ark.'nın yaptıkları çalışmada da, hiçbir diğer klinik faktör değil, sadece yüksek serum AST düzeyi histolojik progresyonla ilişkili bulunmuştur (8).

Sonuç olarak; bu çalışma NAYKH tanısı ile takip edilen olguların ortalama 4.8 yıl ara ile yapılan ikinci biyopsilerinde yaklaşık üçte birinde histolojik ilerleme olduğunu göstermiştir. Yaş, cinsiyet, VKi ve ikinci biyopsi anındaki AST düzeyi histolojik progresyonla ilişkili faktörler olarak karşımıza çıkmıştır. Göreceli olarak genç yaşlarda hastalık progresyonunun hızlı olması nedeniyle ilk biyopsi zamanının çok gecikmemesi ve biyopside NAS skoru düşük sap- 
tanan, ALT düzeyleri normal sınırlarda seyreden olgularda ise fibrozis progresyonunu göstermede ikinci biyopsiyi yapmak için acele edilmemesi gerektiği düşünülmüştür. Ayrıca iyi glisemik kontrol ve yaşam tarzı modifikasyonu

\section{KAYNAKLAR}

1. Schaffner $F$, Thaler $H$. Nonalcoholic fatty liver disease. Prog Liver Dis 1986:8:283-98.

2. Sheth SG, Gordon FD, Chopra S. Nonalcoholic steatohepatitis. Ann Intern Med 1997;126:137-45.

3. Matteoni CA, Younossi ZM, Gramlich T, et al. Nonalcoholic fatty liver disease: a spectrum of clinical and pathological severity. Gastroenterology 1999;116:1413-9.

4. Reid AE. Nonalcoholic steatohepatitis. Gastroenterology 2001;121: 710-23.

5. Becker $U$, Deis $A$, Sorenson $T L$, et al. Prediction of risk of liver disease by alcohol intake, sex and age: a prospective population study. Hepatology 1996;23:1025-9.

6. Maxwell JD, Sanderson I, Butler WH, Gazet JC, Pilkington TR. Hepatic structure and function after modified jejunoileal bypass surgery for obesity. Br Med J 1977;2:726-9.

7. Ludwig J, Viggiano TR, McGill DB, Oh BJ. Nonalcoholic steatohepatitis: Mayo Clinic experiences with a hitherto unnamed disease. Mayo Clin Proc 1980;55:434-8.

8. Teli MR, James OF, Burt AD, Bennett MK, Day CP. The natural history of nonalcoholic fatty liver: a follow-up study. Hepatology 1995;22:1714-9.

9. Powell EE, Cooksley WG, Hanson R, et al. The natural history of nonalcoholic steatohepatitis: a follow-up study of forty-two patients for up to 21 years. Hepatology 1990;11:74-80.

10. Harrison SA, Torgerson S, Hayashi P. The natural history of non-alcoholic fatty liver disease: a clinical histopathological study. Am J Gastroenterol 2003;98:2042-7.

11. Marrero JA, Fontana RJ, Su GL, et al. NAFLD may be a common underlying liver disease in patients with hepatocellular carcinoma in the United States. Hepatology 2002;36:1349-54.

12. Propst A, Propst T, Judmaier G, Vogel W. Prognosis in nonalcoholic steatohepatitis. Gastroenterology 1995;108:1607.

13. Angulo P, Keach J, Batts K, Lindor K. Independent predictors of liver fibrosis in patients with nonalcoholic steatohepatitis. Hepatology 1999;30:1356-62.

14. Adams LA, Sanderson S, Lindor KD, Angulo P. The histological course of nonalcoholic fatty liver disease: a longitudinal study of 103 patients with sequential liver biopsies. J Hepatol 2005;42:1328. ile kilo kontrolünün sağlanması histolojik progresyon açısından önem taşımaktadır.

\section{"Tüm yazarlar herhangi bir çıkar çatışması olmadı̆̆ı- nı beyan ederler."}

15. Dixon JB, Bhathal PS, O'Brien PE. Nonalcoholic fatty liver disease: predictors of nonalcoholic steatohepatitis and liver fibrosis in the severely obese. Gastroenterology 2001;121:91-100.

16. Colicchio P, Tarantino G, del Genio F, et al. Non-alcoholic fatty liver disease in young adult severely obese non-diabetic patients in south Italy. Ann Nutr Metab 2005;49:289-95.

17. Angulo P. NAFLD, obesity, and bariatric surgery. Gastroenterology 2006;130:1848-52.

18. Stranges S, Dorn JM, Muti $P$, et al. Body fat distribution, relative weight, and liver enzyme levels: a population-based study. Hepatology 2004;39:754-63.

19. American Diabetic Association. Clinical practice recommendations 2000. Diabetes Care 2000;23(Suppl 1):4-19.

20. Health NIH: Clinical guidelines on the identification, evaluation and treatment of overweight and obesity in adults: The evidence report. Obes Res Obes Res 1998;6(Suppl 2):51S-209S.

21. Harold E. Lebovitz. Clinician's Manual on Insulin Resistance 2002;p:5.

22. Kleiner DE, Brunt EM, Van Natta M, et al; Nonalcoholic Steatohepatitis Clinical Research Network. Design and validation of a histological scoring system for nonalcoholic fatty liver disease. Hepatology 2005;41:1313-21.

23. Argo CK, Northup PG, Al-Osaimi AM, Caldwell SH. Systematic review of risk factors for fibrosis progression in non-alcoholic steatohepatitis. J Hepatol 2009;51:371-9.

24. Merriman RB, Ferrell LD, Pati MG, et al. Correlation of paired liver biopsies in morbidly obese patients with suspected nonalcoholic fatty liver disease. Hepatology 2006;44:874-80.

25. Fassio E, Alvarez E, Dominguez N, Landeira G, Longo C. Natural history of nonalcoholic steatohepatitis: a longitudinal study of repeat liver biopsies. Hepatology 2004;40:820-6.

26. Das K, Das K, Mukherjee PS, et al. Nonobese population in a developing country has a high prevalence of nonalcoholic fatty liver and significant liver disease. Hepatology 2010;51:1593-602. 